\title{
Improving Mobility in Critically Ill Patients in a Tertiary Care ICU: Opportunities and Challenges
}

\author{
Sneha Mohan ${ }^{1}$, Sristi Patodia ${ }^{2}$, Sudha Kumaravel ${ }^{3}$, Ramesh Venkataraman ${ }^{4}$, Bharath Kumar Tirupakuzhi Vijayaraghavan ${ }^{5}$
}

\begin{abstract}
Background: Patients in the intensive care unit (ICU) are subjected to prolonged bed rest secondary to critical illness and related therapies. Data suggest that such bed rest can have adverse consequences on the post-discharge quality of life. There is limited data from India on mobilization practices. We undertook a quality improvement (QI) initiative to understand our mobilization practices, identify challenges, and test interventions. Materials and methods: We carried out a three-phase QI project, and the study was conducted in our 24-bedded ICU. Pre-intervention and post-intervention mobilization performance and scores were analyzed. We also recorded data on adverse events and barriers to mobilization. Descriptive statistics were used to report all the results.

Results: A total of 140 patients ( 1,033 patient days) and 207 patients ( 932 patient days) were included in our initial audit and post-implementation audit, respectively. In pre-implementation, $31.3 \%$ of patients were mobilized with an average mobility score of 2 and this improved to $57.9 \%$ with average mobility score of 3.4. Additionally, we demonstrated improvements in the mobility scores of our intubated patients (49.8\% achieving a mobility score of 3-5 as compared to $16.7 \%)$.

Conclusion: A multidisciplinary approach is feasible and resulted in significant improvements in early mobilization among critically ill adults. Keywords: Intensive care units, Quality improvement, Rehabilitation.

Indian Journal of Critical Care Medicine (2021): 10.5005/jp-journals-10071-23438
\end{abstract}

\section{INTRODUCTION}

Patients in the intensive care unit (ICU) are subjected to prolonged periods of bed rest secondary to critical illness and the treatments they receive such as mechanical ventilation, vasopressors, and renal replacement therapy. Data suggest that physical impairment can affect nearly half of the patients admitted to ICUs and that $50 \%$ of those are unable to return to premorbid levels of functional activity at 1 year after discharge. ${ }^{1}$ This ICU-acquired weakness is associated with poor functional outcomes and increased mortality. ${ }^{2-4}$ Studies from high-income countries (HICs) have described their ICU mobilization practices ${ }^{5-8}$ and demonstrated that early, active mobilization is beneficial..$^{9-13}$ Mobilization is associated with shorter duration of ventilation, ${ }^{12-14}$ decreased length of stay, ${ }^{15,16}$ and better functional outcomes. ${ }^{17}$

There is limited data from India and South Asia on mobilization practices for critically ill patients. In a cross-sectional observational study from China, authors reported mobilizing patients predominantly in bed (98\%) with very few centers reporting walking or higher levels of mobility (2.4\%). ${ }^{18}$ In India, a survey among ICU physicians reported that $92 \%$ of respondents were aware of the benefits of mobilization, yet remained apprehensive of adverse events. ${ }^{19}$ Given the potential constraints in resources and cultural diversity, it is likely that ICUs in India and other lower-middle-income countries face distinct challenges.

We undertook a quality improvement (QI) initiative at a large tertiary care ICU in India to understand our mobilization practices, identify challenges, and test interventions to improve mobilization.

\section{Materials and Methods}

We carried out a three-phase QI project comprising an initial audit, an intervention design phase, and a follow-up phase. The study

\footnotetext{
${ }^{1-5}$ Department of Critical Care Medicine, Apollo Hospitals, Chennai, Tamil Nadu, India
}

Corresponding Author: Bharath Kumar Tirupakuzhi Vijayaraghavan, Department of Critical Care Medicine, Apollo Hospitals, Chennai, Tamil Nadu, India, Phone: +919591100655, e-mail: bharathkumartv@ gmail.com

How to cite this article: Mohan S, Patodia S, Kumaravel S, Venkataraman R, Vijayaraghavan BKT. Improving Mobility in Critically III Patients in a Tertiary Care ICU: Opportunities and Challenges. Indian J Crit Care Med 2021;25(1):34-42.

Source of support: Nil

Conflict of interest: None

was conducted in our 24-bedded, medical-surgical-neurotrauma ICU. The ICU admits approximately 1,500 patients/year and has a nursing ratio of 1:1 for invasively ventilated patients and 1:2 for other patients. There are two physiotherapists available in the morning shift and one in the evening shift. For the initial audit, we included all patients with ICU stay $>24$ hours admitted during June and July 2018 and recorded their demographics and disease characteristics. Eligibility for mobilization was assessed using predefined criteria that were developed in-house (Appendix 1). These criteria were adapted from the existing literature on safety thresholds for mobilization ${ }^{20,21}$ and incorporated safety features for the neurocritical care cohort as well. For instance, there were specific criteria that would preclude mobility for these patients (inability to follow commands, intracranial pressure $\geq 20$, presence of an external ventricular drain (EVD) or a lumbar drain, specific objections or concerns from the treating neurology or neurosurgical team), all of which ensured safety. Mobilization provided and the highest level achieved were documented using

() The Author(s). 2021 Open Access This article is distributed under the terms of the Creative Commons Attribution 4.0International License (https://creativecommons. org/licenses/by-nc/4.0/), which permits unrestricted use, distribution, and non-commercial reproduction in any medium, provided you give appropriate credit to the original author(s) and the source, provide a link to the Creative Commons license, and indicate if changes were made. The Creative Commons Public Domain Dedication waiver (http://creativecommons.org/publicdomain/zero/1.0/) applies to the data made available in this article, unless otherwise stated. 
the validated ICU mobility scale (IMS). ${ }^{22}$ Adverse events and barriers to mobilization on eligible days were recorded.

Based on the results of the initial audit, we designed a multifaceted intervention to aid ICU staff in improving mobilization among critically ill patients. Our tool leveraged the existing knowledge that a coordinated approach involving all the stakeholders is essential for successful outcomes. ${ }^{23-25}$ The intervention protocol (Flowchart 1) systematically involved ICU nurses, physiotherapists, and physicians at various levels to achieve these goals while ensuring patient safety.

One of the barriers identified for delays and failure of mobilization was the absence of physician orders. After a departmental meeting with all the intensive care physicians in the team, we introduced an opt-out concept. In this model, all patients were considered eligible for mobilization unless they had a predefined clinical contraindication (Appendix 1), and the mandate for a physician order for mobilization was done away with. Patients were screened by the overnight staff nurses for any potential contraindications to mobilization. The nurse would then indicate fitness for mobilization through the means of a simple color-coded bedside plaque-green for eligible and red for ineligible (Fig. 1). If the bedside plaque indicated green, the physiotherapist on the morning shift was authorized to proceed with the day's mobilization plan.

To ensure safety of the intervention, we mandated the presence of a physiotherapist, nurse, and a support staff for mobilization of critically ill adults. For intubated patients, additionally, we ensured the presence of a doctor to support and monitor mobilization. This

Flowchart 1: Protocol for mobilization in the intensive care unit

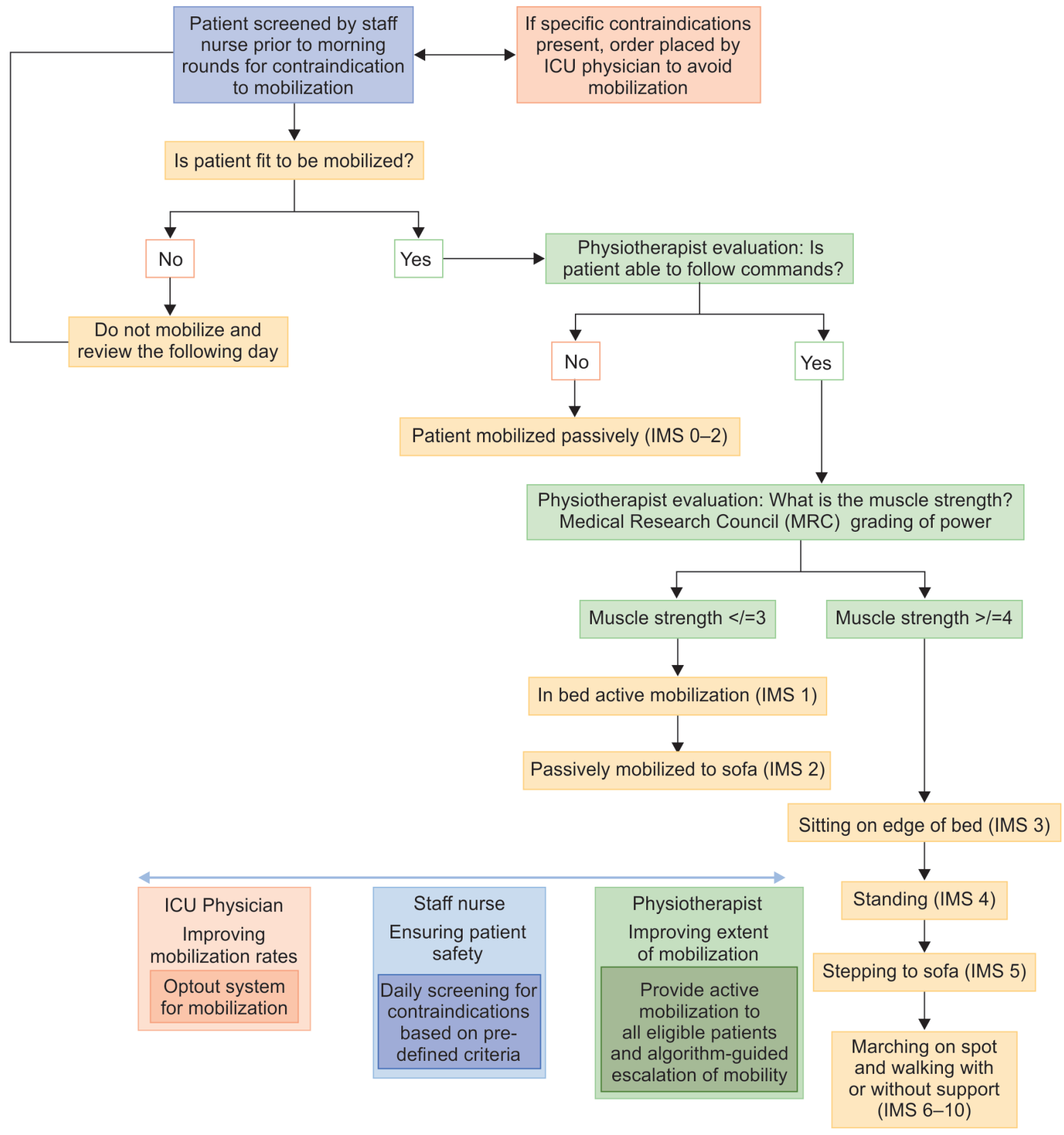

ICU, intensive care unit; IMS, ICU mobility scale 


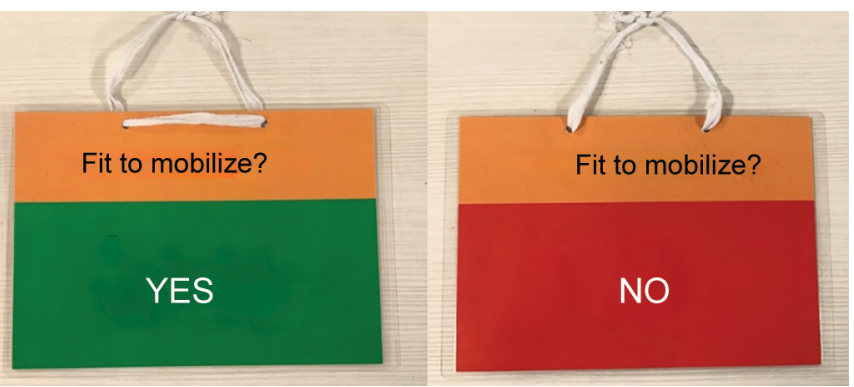

Fig. 1: Bedside plaque

approach was mandated for the first few sessions of mobilization and recommended for all further sessions that involved intubated patients.

The second major barrier identified to mobilization was related to intensive care procedures such as placement of endotracheal tubes, hesitation to mobilize on the day of extubation/planned ICU transfer out, apprehension due to presence of dialysis catheter, and other invasive lines such as central venous catheters. We identified two of these as modifiable barriers-lack of mobilization on extubation days/planned transfer out days and mobilization in the presence of a invasive lines (dialysis catheters, central venous catheters, etc.). We met with the nursing teams and through repeated educational sessions attempted to dispel apprehensions regarding the same.

Another issue identified during the audit was that there was no graded escalation of mobilization goals for patients who were being mobilized. For instance, once patients were moved to a couch, no further attempts would be made on subsequent days to ambulate, even when patients were otherwise stable. To address this, we worked closely with the physiotherapy team and encouraged the use of an algorithm to aid in escalation of the level of mobilization in order to achieve the highest activity possible for a patient on a given day.

As the intervention involved multiple components, it was designed and tested over 2 months (August and September 2018) and formally rolled out by October 2018. The implementation phase continued from October 2018 to January 2019. Interim informal audits were undertaken by the second author (SP) on two occasions (in November 2018 and again in January 2019) to evaluate compliance with elements of the intervention and to identify residual barriers. Findings from these audits were fed back to all the stakeholders. We have reported the findings of these interim audits in our results section.

While no formal input was sought from patients in designing the intervention, informal consultations were held with patients and families to identify challenges that they faced. The feedback was consistent regarding a desire to be mobilized, preferably earlier in the day. The results from our audit also confirmed that patient refusal for mobilization was a barrier on only 3 out of 97 patient days.

The final phase of post-implementation evaluation was undertaken over a period of 2 months between mid-February to mid-April 2019. To standardize the comparison between the preand post-implementation phase, the same eligibility criteria for mobilization were used and data were collected using the same tools as used for the initial audit.
Table 1: Patient characteristics

\begin{tabular}{|c|c|c|c|}
\hline & Pre-intervention & Post-intervention & $p$ value \\
\hline Number of patients & 140 & 207 & - \\
\hline $\begin{array}{l}\text { Total number of } \\
\text { patient days }\end{array}$ & 1,033 days & 932 days & - \\
\hline Mean age $( \pm S D)$ & $57 \pm 18$ & $58 \pm 17$ & 0.6 \\
\hline Male (percentage) & $87(62.1 \%)$ & 145 (70\%) & 0.12 \\
\hline $\begin{array}{l}\text { Disease severity: } \\
\text { mean APACHE IV } \\
\text { score } \pm \text { SD }\end{array}$ & $89 \pm 33.7$ & $84.6 \pm 31.8$ & 0.21 \\
\hline \multicolumn{4}{|c|}{ Diagnosis at admission } \\
\hline Medical (\%) & 109 (77.9\%) & $156(75.4 \%)$ & 0.58 \\
\hline Surgical (\%) & $21(15 \%)$ & $41(19.8 \%)$ & 0.25 \\
\hline Trauma (\%) & $10(7.1 \%)$ & $10(4.8 \%)$ & 0.36 \\
\hline $\begin{array}{l}\text { Mean length of ICU } \\
\text { stay } \pm S D\end{array}$ & 7.4 days \pm 6.3 & 5.4 days \pm 4.8 & 0.0009 \\
\hline \multicolumn{4}{|l|}{ Ventilation method } \\
\hline $\begin{array}{l}\text { Endotracheal } \\
\text { tube (\%) }\end{array}$ & 480 (46.47\%) & $406(43.6 \%)$ & 0.19 \\
\hline $\begin{array}{l}\text { Tracheostomy } \\
\text { tube (\%) }\end{array}$ & $193(18.68 \%)$ & $61(6.5 \%)$ & $<0.001$ \\
\hline $\begin{array}{l}\text { Noninvasive } \\
\text { ventilation/room } \\
\text { air }(\%)\end{array}$ & $360(34.85 \%)$ & 465 (49.9\%) & $<0.001$ \\
\hline
\end{tabular}

We use descriptive statistics to report all the results. Categorical variables are reported as percentages and continuous variables as mean and standard deviation (or median and interquartile range). For the primary analysis of comparison of proportion of mobilized days, a chi-square test was applied.

As the entire project was conceived, designed, and implemented as a unit-based QI initiative, the institutional ethics committee was not approached for approval. A verbal consent was sought from patients before mobilizing them.

\section{RESULTS}

\section{Initial Audit}

A total of 140 patients were followed spanning 1,033 patient days (Table 1). About $62.1 \%$ were male, with average age of 57 (SD 18 years). Admissions were predominantly medical (77.9\%) with mean APACHE IV score of 89 (SD 33.7). Length of stay in the ICU averaged 7.4 days (SD 6.3). Of 1,033 patient days, they were invasively ventilated on 673 days (65.2\%).

A total of 91 (65\%) of 140 patients were mobilized at least once during their ICU stay. The patterns of mobilization across the 1,033 patient days are summarized in Table 2. Patients were eligible for mobilization according to our predefined criteria on 373 days (36.1\%) and were mobilized on 276 of these days (74\%). Interestingly, patients were mobilized an additional 47 days despite being deemed ineligible by predefined criteria (perhaps, a consequence of conservative eligibility criteria), increasing the total number of mobilized days to 323 (31.3\% of total patient days). On average, the IMS level achieved was 2 corresponding to being passively moved out of bed.

In the initial audit, adverse events were noted only on 6 days (1.9\%). These events were marginal derangement of physiological parameters such as respiratory and heart rate, 
Table 2: Mobilization level achieved

\begin{tabular}{|c|c|c|c|}
\hline & Pre-intervention & Post-intervention & $p$ value \\
\hline All patient days & $N=1033$ & $N=932$ & \\
\hline Total number of days mobilized & $\begin{array}{l}323(31.3 \% \text { of } \\
\text { total days) }\end{array}$ & $\begin{array}{l}540 \text { ( } 57.9 \% \text { of } \\
\text { total days) }\end{array}$ & $<0.00001$ \\
\hline Average mobilization per IMS & 2 & 3.4 & \\
\hline 1-Active movement in bed (\%) & $193(59.7 \%)$ & $161(29.8 \%)$ & $<0.001$ \\
\hline 2-Mobilized passively out of bed (\%) & $68(21.1 \%)$ & $44(8.1 \%)$ & $<0.001$ \\
\hline $3-5-$ Sitting on side of bed, stepping to chair, standing (\%) & $54(16.7 \%)$ & $269(49.8 \%)$ & $<0.001$ \\
\hline 6-10-Marching, walking with and without support (\%) & $8(2.5 \%)$ & $66(12.2 \%)$ & $<0.001$ \\
\hline \multicolumn{4}{|l|}{ Endotracheal tube } \\
\hline Number of days with endotracheal tube (\%) & $480(46.47 \%)$ & $406(43.6 \%)$ & 0.19 \\
\hline Number of days mobilized & 80 & 110 & \\
\hline IMS 1 (\%) & $78(97.5 \%)$ & $80(72.7 \%)$ & $<0.001$ \\
\hline IMS 2 (\%) & $1(1.25 \%)$ & $7(6.4 \%)$ & 0.083 \\
\hline IMS 3-5 (\%) & $1(1.25 \%)$ & $20(18.2 \%)$ & 0.0002 \\
\hline IMS 6-10 (\%) & 0 & $3(2.7 \%)$ & 0.13 \\
\hline \multicolumn{4}{|l|}{ Tracheostomy } \\
\hline Number of days with tracheostomy & $193(18.68 \%)$ & $61(6.5 \%)$ & $<0.001$ \\
\hline Number of days mobilized & 69 & 45 & \\
\hline IMS 1 (\%) & $22(31.9 \%)$ & $19(42.2 \%)$ & 0.26 \\
\hline IMS 2 (\%) & $42(60.9 \%)$ & 0 & $<0.001$ \\
\hline IMS 3-5 (\%) & $5(7.2 \%)$ & $26(57.8 \%)$ & $<0.001$ \\
\hline IMS 6-10 (\%) & 0 & 0 & - \\
\hline
\end{tabular}

without any significant clinical consequence or interruption in the mobilization session. On ineligible days (660 days, $63.9 \%)$, the impaired neurological status ( 402 days, $61 \%$ ) was the most common contraindication to mobilization.

Barriers to mobilization (Table 3) were noted on 97 of the 373 eligible days (26\%) and included concerning symptoms in the patient on 35 days (36.1\%), minor procedures on 31 days (32\%), and shifting of patients in and out of the ICU on 15 days (15.5\%). Missing physician orders and absence of couch for mobilization were other barriers noted. Based on these results, we aimed for an improvement of $\geq 10 \%$ (i.e., from 31.3 to over $41 \%$ ) in the total number of mobilized days as our primary outcome over a period of 6 months.

\section{Results of the Interim Informal Audits}

We performed two interim informal audits to evaluate compliance with the elements of the intervention and to assess barriers/ challenges to implementation.

Our first audit was completed over a period of 1 week in December 2018. We found that nursing staff apprehension over mobilizing intubated/tracheostomized patients remained and that such patients were marked "no" for mobilization despite meeting eligibility criteria. This was addressed through several sessions to educate nurses on the benefits and safety of mobilizing intubated patients and by offering the presence of a physician to supervise and help.

The second issue that our audit identified was apprehension among physiotherapists on achieving higher levels of mobilization. Once patients were mobilized to a couch (IMS score 5), no attempt would be made to advance the activity score regardless of patient fitness. We held multiple meetings with physiotherapists to educate and engage on the benefits of ambulation and to address residual
Table 3: Barriers to mobilization on eligible days in pre-intervention audit

\begin{tabular}{ll}
\hline Barriers & $\begin{array}{l}\text { Number of patient days } \\
\text { (percentage of total, } n=97)\end{array}$ \\
\hline $\begin{array}{l}\text { Concerning symptom or sign in } \\
\text { patient }\end{array}$ & $35(36.1 \%)$ \\
$\begin{array}{l}\text { Procedures } \\
\text { OT procedures or invasive }\end{array}$ & $31(32 \%)$ \\
tests & 8 \\
Intubated that day & 4 \\
Extubated that day & 7 \\
Tracheostomy & 1 \\
Dialysis & 5 \\
Others & 6 \\
Shifting into and out of ICU & $15(15.5 \%)$ \\
Night admission (after 7 pm) & 7 \\
Day of admission & 2 \\
Day of shifting out & 6 \\
Presence of lines or tubes (not & $8(8.2 \%)$ \\
considered contraindication) & \\
Absence of doctor's orders & $4(4.1 \%)$ \\
Patient refusal & $3(3.1 \%)$ \\
No couch available & $1(1 \%)$ \\
\hline
\end{tabular}

concerns from their perspective. One of the issues that emerged from these meetings was the lack of adequate couches to move patients out of bed. We brought this to the attention of the hospital administrators, who were very responsive and promptly addressed this.

Our second audit in the month of January identified only residual concerns from some of the nurses regarding mobilization 
of intubated patients. One of the reasons for this was the induction of new nurses into the ICU team, who needed further sessions of education and engagement. No other major concerns were flagged during this audit.

\section{Post-implementation Audit}

We conducted our final audit from February 15, 2019 to April 15, 2019. A total of 207 patients were followed over 932 days (Table 1). About $70 \%$ were male with an average age of 58 years (SD 17 years). Medical conditions predominated among admissions during this period at $75.4 \%$ with a mean APACHE IV score of 84.6 (SD 31.8). Patients' duration of stay in the ICU averaged 5.4 days (SD 4.8). Out of 932 patient days, they were invasively ventilated on 467 (50.1\%). Of 207 patients, 157 (75.8\%) were mobilized at least one of the days.

Patients were found to be eligible for mobilization on 466 days (50\%) and were successfully mobilized on all of these days (100\% of eligible days). Patients were also mobilized on an additional 74 days, bringing the total number of mobilized days to 540 (57.9\%). We were thus able to achieve our stated aim of at least $10 \%$ improvement over a 6-month period. On average the IMS was 3.4 with IMS 3 corresponding to sitting on the side of the bed (Table 2).

In the initial audit, the number of intubated/tracheostomized patients who achieved an IMS of 3 or above was only 6 . Post implementation this number increased to 49 (Table 2). Adverse events noted during mobilization were slightly higher, occurring during 13 mobilization sessions (2.4\%). Of these, a majority (10) were minor physiological derangements, which did not require any intervention or cessation of mobilization. In the remaining three episodes, patients who were mobilized out of bed were noted to have hypotension requiring intervention and discontinuation of mobilization.

Among the 466 ineligible days, impaired neurological status was once again the most common reason [227 days (48.7\%)]. Informal feedback from nurses, physiotherapists, and physicians indicated a higher level of enthusiasm and engagement in early mobilization, perhaps reflecting the beginnings of a culture change.

\section{Discussion}

Our study describes the mobilization practices from a large tertiary care ICU in Southern India and the challenges and barriers. Our initial audit revealed a low mobilization rate of $31.3 \%$ and that, patients when mobilized, achieved a low mobilization score (average IMS of 2). Our collaborative QI initiative resulted in important improvements on both counts-we were able to mobilize patients on $57.9 \%$ of their ICU days and we were able to improve the highest level of mobilization achieved (average IMS of 3.4).

Internationally, there is wide variability in the performance of ICUs as far as early mobilization is concerned. Our initial rates (31.3\%) were lower compared to data from one mixed medicalsurgical ICU in Australia, which reported mobilization rates of just over $50 \% .{ }^{5}$ Conversely, our baseline rates of mobilization were comparable to a point-prevalence study across 42 ICUs in the United States (mobilization rate of $32 \%$ ). ${ }^{6}$ Globally, barriers to mobilization include disease severity, sedation requirement, mechanical ventilation, presence of multiple invasive lines and tubes, and physiological instability. ${ }^{5,26,27}$ Broadly, the barriers we identified are similar to those reported in other studies, chief among which is nonmodifiable disease-related factors. Some specific barriers such as lack of couches and manpower, which were reported during our informal audits, are likely common to other resource-limited settings.
Our multidisciplinary QI initiative resulted in important improvements in the rates of mobilization and in the average activity score of patients during this period. Harris et al. ${ }^{28}$ in a physical therapist-driven QI study engaging various stakeholders were able to increase the number of physical therapy evaluations from 364 to 542 over a period of 1 year. However, their study did not describe the actual improvements in mobilization scores achieved. In a study from the UK, van Willigen et al. ${ }^{29}$ were able to demonstrate the success of an ICU-based QI program in shortening the time to first mobilization and in decreasing length of stay. While they used a predominantly education and engagement-based approach, our intervention consisted of nurse-based screening for eligibility, simple bedside placards indicating readiness, physician opt out, and goal-based physiotherapy with daily targets for improving the mobilization score. This multipronged and locally relevant approach provided us with optimal results. Importantly, we were able to bring about significant improvements in a short time span of 6 months. In contrast, and surprisingly, the Willigen study performed improvement cycles over a period of nearly 4 years to demonstrate improvements.

The mobilization of intubated patients poses major challenges across ICUs. The presence of the endotracheal tube, need for varying degrees of sedation, apprehensions about tube dislodgement, and disconnections mean that this group of critically ill patients get mobilized the least. Data from our informal interim audits also confirmed the fears and apprehensions of the nursing and physiotherapy teams in mobilizing intubated patients. However, by virtue of their illness severity, they are also the group at highest risk for complications resulting from immobility. In a study of mechanically ventilated patients from 12 ICUs across Australia and New Zealand, the investigators found that of 1,288 planned mobilization episodes, no mobilization occurred on $84 \%$ of these occasions. ${ }^{6}$ Our baseline data were similar in that we were able to mobilize intubated patients only on $16.7 \%$ of patient days. With the QI effort, we were able to increase this to $27 \%$ of patient days. We were also able to bring about improvements in the proportion of intubated patients achieving higher mobilization scores (IMS 3-5 of $57.8 \%$ as against $7.2 \%$ at baseline).

Rates of adverse events directly related to mobilization are low in the published literature, ${ }^{9,11}$ and our data are also consistent with these findings. Though there was a slight increase in adverse events following the intervention, this is likely a result of improved mobilization and an increase in out of bed mobilization. Importantly, only three episodes needed discontinuation of mobilization. Overall, it is evident that with appropriate screening and adequate support from medical staff, early mobilization is safe.

Our study has several important strengths. This is the first study from India describing in detail the practices and challenges to mobilization and in demonstrating the feasibility and success of a QI program. We were able to include a large number of patient days for both our baseline measurement and for the postimplementation audit (1,033 days and 932 days, respectively). Three dedicated investigators independently collected data for baseline measurement and in the post-implementation phase and treating teams were blinded to the audits. Our QI initiative was truly collaborative and multidisciplinary, and our approach was locally relevant and unique.

Our study is limited by the inclusion of a single center in Southern India and thus our results may not be generalizable to other ICUs in the country, where resources are variable. While 
our unit also deals with resource challenges, we have dedicated ICU physiotherapists and our nursing ratio for ventilated patients is 1:1. This is unlikely to be the case in most tertiary-level ICUs in India and across the South Asian region. However, it is important to note that we did not use any complex or expensive mobilization equipment in our ICU and improvements achieved were mostly through a process of culture change. We recognize that sustaining these improvements will remain a challenge. To this end, we plan to identify and appoint two mobilization champions among our nursing and physiotherapy staff, who will continue to monitor mobilization rates on a biweekly basis and provide feedback to all the stakeholders. The mobilization champions will also continue to spearhead efforts (with education and engagement) to improve further on the successes of this program.

Early mobilization is feasible and safe in resource-limited setups. A multidisciplinary practical collaborative approach resulted in significant improvements in achieving early mobilization. Future research must focus on identifying opportunities and challenges for early mobilization of critically ill adults from other resourceconstrained settings in the South Asian region.

\section{Acknowledgments}

The authors would like to thank Dr Nagarajan Ramakrishnan, Director of Critical Care at Apollo Hospitals, Greams Road, Chennai, Mr Mahendran Subramanian (Lead Physiotherapist for Critical Care), and Dr Lakshmi Ranganathan (Research Manager for Chennai Critical Care Consultants) for their contributions to the implementation of the project and for inputs to the manuscript.

\section{References}

1. Engel HJ, Needham DM, Morris PE, Gropper MA. ICU early mobilization: from recommendation to implementation at three medical centers. Crit Care Med 2013;41(9 Suppl 1)::S69-:S80. DOI: 10.1097/CCM.0b013e3182a240d5.

2. De Jonghe B, Sharshar T, Lefaucheur J-P, Authier FJ, Durand-Zaleski I, Boussarsar $M$, et al. Paresis acquired in the intensive care unit: a prospective multicenter study. JAMA 2002;288(22):2859-2867. DOI: 10.1001/jama.288.22.2859.

3. Jolley SE, Bunnell $A E$, Hough CL. ICU-acquired weakness. Chest 2016;150(5):1129-1140. DOI: 10.1016/j.chest.2016.03.045.

4. Hermans G, Van Mechelen H, Clerckx B, Vanhullebusch T, Mesotten D, Wilmer A, et al. Acute outcomes and 1-year mortality of intensive care unit-acquired weakness. A cohort study and propensity-matched analysis. Am J Respir Crit Care Med 2014;190(4):410-420. DOI: 10.1164/ rccm.201312-22570C.

5. Brock C, Marzano V, Green M, Wang J, Neeman T, Mitchell I, et al. Defining new barriers to mobilisation in a highly active intensive care unit - have we found the ceiling? an observational study. Heart Lung 2018;47(4):380-385. DOI: 10.1016/j.hrtlng.2018.04.004.

6. Jolley SE, Moss M, Needham DM, Caldwell E, Morris PE, Miller RR, et al. Point prevalence study of mobilization practices for acute respiratory failure patients in the United states. Crit Care Med 2017;45(2):205-215. DOI: $10.1097 / C C M .0000000000002058$.

7. TEAM Study Investigators, Hodgson C, Bellomo R, Berney S, Bailey $\mathrm{M}$, Buhr $\mathrm{H}$, et al. Early mobilization and recovery in mechanically ventilated patients in the ICU: a bi-national, multi-centre, prospective cohort study. Crit Care 2015;19(1):81. DOI: 10.1186/s13054-015-0765-4.

8. Nydahl P, Ruhl AP, Bartoszek G, Dubb R, Filipovic S, Flohr HJ, et al. Early mobilization of mechanically ventilated patients: a 1-day point- prevalence study in Germany. Crit Care Med 2014;42(5):1178-1186. DOI: $10.1097 / C C M .0000000000000149$.

9. NydahI P, Sricharoenchai T, Chandra S, Kundt FS, Huang M, Fischill M, et al. Safety of patient mobilization and rehabilitation in the intensive care unit. systematic review with meta-analysis. Ann Am Thorac Soc 2017;14(5):766-777. DOI: 10.1513/AnnalsATS.201611-843SR.

10. Tipping CJ, Harrold M, Holland A, Romero L, Nisbet T, Hodgson $\mathrm{CL}$. The effects of active mobilisation and rehabilitation in ICU on mortality and function: a systematic review. Intensive Care Med 2017;43(2):171-183. DOI: 10.1007/s00134-016-4612-0.

11. Adler J, Malone D. Early mobilization in the intensive care unit: a systematic review. Cardiopulm Phys Ther J 2012;23(1):5-13. DOI: 10.1097/01823246-201223010-00002.

12. Schweickert WD, Pohlman MC, Pohlman AS, Nigos C, Pawlik $\mathrm{AJ}$, Esbrook $\mathrm{CL}$, et al. Early physical and occupational therapy in mechanically ventilated, critically ill patients: a randomised controlled trial. Lancet 2009;373(9678):1874-1882. DOI: 10.1016/ S0140-6736(09)60658-9.

13. Schaller SJ, Anstey M, Blobner M, Edrich T, Grabitz SD, Gradwohl-Matis $\mathrm{I}$, et al. Early, goal-directed mobilisation in the surgical intensive care unit: a randomised controlled trial. Lancet 2016;388(10052):13771388. DOI: 10.1016/S0140-6736(16)31637-3.

14. Balas MC, Vasilevskis EE, Olsen KM, Schmid KK, Shostrom V, Cohen $M Z$, et al. Effectiveness and safety of the awakening and breathing coordination, delirium monitoring/management, and early exercise/ mobility bundle. Crit Care Med 2014;42(5):1024-1036. DOI: 10.1097/ CCM.0000000000000129.

15. Needham DM, Korupolu R, Zanni JM, Pradhan P, Colantuoni E, Palmer $\mathrm{JB}$, et al. Early physical medicine and rehabilitation for patients with acute respiratory failure: a quality improvement project. Arch Phys Med Rehabil 2010;91(4):536-542. DOI: 10.1016/j.apmr.2010.01.002.

16. Morris PE, Goad A, Thompson C, Taylor K, Harry B, Passmore L, et al. Early intensive care unit mobility therapy in the treatment of acute respiratory failure. Crit Care Med 2008;36(8):2238-2243. DOI: 10.1097/ CCM.0b013e318180b90e.

17. Burtin C, Clerckx B, Robbeets C, Ferdinande P, Langer D, Troosters $\mathrm{T}$, et al. Early exercise in critically ill patients enhances shortterm functional recovery. Crit Care Med 2009;37(9):2499-2505. DOI: 10.1097/CCM.0b013e3181a38937.

18. Zhu Y, Xia L, Li G. Management of early mobilization in intensive care units: a multicenter cross-sectional study. Frontiers of Nursing 2018;5(4):291-299. DOI: 10.1515/fon-2018-0043.

19. Ramakrishnan N, Todi S, Myatra SN, Dash SK, Kansal S, Chawla R. Current practices of mobilization, analgesia, relaxants and sedation in Indian ICUs: a survey conducted by the Indian society of critical care medicine. Indian J Crit Care Med 2014;18(9):575-584. DOI: 10.4103/0972-5229.140146.

20. da Conceição TMA, Gonzáles Al, de Figueiredo FCXS, et al. Safety criteria to start early mobilization in intensive care units. Systc Rev Rev Bras Ter Intensiva 2017;29(4):509-519.

21. Hodgson CL, Stiller K, Needham DM, Tipping CJ, Harrold M, Baldwin $\mathrm{CE}$, et al. Expert consensus and recommendations on safety criteria for active mobilization of mechanically ventilated critically ill adults. Crit Care 2014;18(6):658. DOI: 10.1186/s13054-014-0658-y.

22. Hodgson C, Berney S, Haines K, et al., Development of a mobility scale for use in a multicentre Australia and New Zealand study: Trial of Early Activity and Mobilisation in ICU. In 2013.

23. Green M, Marzano V, Leditschke IA, Mitchell I, Bissett B. Mobilization of intensive care patients: a multidisciplinary practical guide for clinicians. J MultidiscipHealthc 2016;9:247-256. DOI: 10.2147/JMDH. S99811.

24. Engel HJ, Tatebe S, Alonzo PB, Mustille RL, Rivera MJ. Physical therapist-established intensive care unit early mobilization program: quality improvement project for critical care at the university of California San Francisco medical center. Phys Ther 2013;93(7):975985. DOI: 10.2522/ptj.20110420. 
25. Mah JW, Staff I, Fichandler D, Butler KL. Resource-efficient mobilization programs in the intensive care unit: who stands to win? Am J Surg 2013;206(4):488-493. DOI: 10.1016/j.amjsurg.2013. 03.001 .

26. Leditschke IA, Green M, Irvine J, Bissett B, Mitchell IA. What are the barriers to mobilizing intensive care patients? Cardiopulm Phys Ther J 2012;23(1):26-29. DOI: 10.1097/01823246-201223010-00005.

27. Dubb R, Nydahl P, Hermes C, Schwabbauer N, Toonstra A, Parker $\mathrm{AM}$, et al. Barriers and strategies for early mobilization of patients in intensive care units. Ann Am Thorac Soc 2016;13(5):724-730. DOI: 10.1513/AnnalsATS.201509-586CME.

28. Harris CL, Shahid S. Physical therapy-driven quality improvement to promote early mobility in the intensive care unit. Proc (Bayl Univ Med Cent) 2014:27(3):203-207. DOI: 10.1080/08998280.2014.11929108.

29. van Willigen Z, Collings N, Richardson D, Cusak R. Quality improvement: the delivery of true early mobilization in an intensive care unit. BMJ Qual Improv Rep 2016;5(1):u211734. DOI: 10.1136/ bmjquality.u211734.w4726w4726. 


\section{Appendix 1: Daily Patient Assessment for Mobilization}

1. Date:

2. Patient study number:

3. Patient identification number:

4. Day of stay in the MDCCU:

5. Is the patient ventilated? ETT $\square \quad$ Tracheostomy $\square \quad$ NIV $\square \quad$ None

6. Does the patient have any of the following contraindications to mobilization today?

\begin{tabular}{|c|c|c|}
\hline System & Criteria & Tick \\
\hline \multirow[t]{3}{*}{ Neurologic } & Patient RASS $\leq-3$ or $\geq+2$ (Pt RASS & \\
\hline & Unable to follow commands & \\
\hline & ICP $>20 \mathrm{~mm} \mathrm{Hg}$ (Pt ICP if available___ & \\
\hline \multirow[t]{3}{*}{ Respiratory } & Nonintubated: respiratory rate $>30 \mathrm{bpm}$ at rest $(\mathrm{Pt} \mathrm{RR}$ & \\
\hline & $\mathrm{SpO}_{2}<92 \%$ or NIV with $\mathrm{FiO}_{2}>0.6\left(\mathrm{Pt} \mathrm{SpO}{ }_{2}\right.$ & \\
\hline & Invasive ventilation: $\mathrm{FiO}_{2}>0.6$ or $\mathrm{PEEP}>10\left(\mathrm{Pt} \mathrm{FiO}_{2} \_\right.$PEEP_ & \\
\hline \multirow[t]{5}{*}{ Cardiovascular } & $\mathrm{HR}>110$ at rest $(\mathrm{pt} \mathrm{HR}$ & \\
\hline & MAP $<65$ or $>110($ pt MAP & \\
\hline & $\begin{array}{l}\text { Requirement of two vasopressors OR on one high-dose vasopressor }(>0.1 \mu \mathrm{g} / \mathrm{kg} / \\
\text { minute of noradrenaline or equivalent) (pt vasopressor dose_ }\end{array}$ & \\
\hline & Orthostatic hypotension with fall in BP > 20 mm Hg in SBP/DBP & \\
\hline & Active bleeding & \\
\hline \multirow[t]{5}{*}{ Special lines/tubes } & Femoral dialysis catheter/patient on CRRT & \\
\hline & External ventricular drain & \\
\hline & Temporary pacemaker/transvenous pacemaker & \\
\hline & Lumbar drain & \\
\hline & IABP & \\
\hline \multicolumn{3}{|l|}{ Other } \\
\hline Patient & Patient refusal & \\
\hline
\end{tabular}

7. Can the patient be mobilized? Yes $\square \quad$ No $\square$

8. Was the patient mobilized today? Yes $\square \quad$ No $\square$

9. If patient was not mobilized, what was the reason given by the treating physician/staff nurse/physiotherapist

\begin{tabular}{ll}
\hline Tick & Specify reason \\
\hline
\end{tabular}

ICU physician

Admitting physician

Physiotherapist

Staff nurse

10. During the physical therapy session, was there any adverse event?

\begin{tabular}{lll}
\hline $\begin{array}{l}\text { Displacement of a } \\
\text { tube/line (specify) } \\
\text { Respiratory rate }>30\end{array}$ & Falls & HR>110 \\
$\begin{array}{l}\text { Orthostatic } \\
\text { hypotension }>20 \% \\
\text { fall in SBP/DBP } \\
\mathrm{SpO}_{2}<92 \% \text { or } \mathrm{FiO}_{2}>\end{array}$ & MAP $<65$ or $>110$ & $\begin{array}{l}\text { Arrhythmias (V-tach, } \\
\text { A fib), cardiac arrest }\end{array}$ \\
0.6 or PEEP $>10$
\end{tabular}


11. If patient was successfully mobilized, what was the level reached per the ICU mobilization scale?

\begin{tabular}{|c|c|c|}
\hline Classification & Definition & \\
\hline Nothing, lying in bed & $\begin{array}{l}\text { Passively rolled or passively exercised by staff, but not actively } \\
\text { moving }\end{array}$ & 0 \\
\hline Sitting in bed, exercises in bed & $\begin{array}{l}\text { Any activity in bed, including rolling bridging, active exercises, } \\
\text { cycle ergometry, and active assisted exercises; not moving out of } \\
\text { bad or over the edge of the bed }\end{array}$ & 1 \\
\hline $\begin{array}{l}\text { Passively moved to chair (no } \\
\text { standing) }\end{array}$ & $\begin{array}{l}\text { Hoist, passive lift, or slide transfer to the chair, with no standing or } \\
\text { sitting on the edge of the bed }\end{array}$ & 2 \\
\hline Sitting over edge of bed & $\begin{array}{l}\text { May be assisted by staff, but involves actively sitting over side of } \\
\text { bed with some trunk control }\end{array}$ & 3 \\
\hline Standing & $\begin{array}{l}\text { Weight bearing through the feet in the standing position, with or } \\
\text { without assistance. This may include use of a standing lifter device } \\
\text { or tilt table }\end{array}$ & 4 \\
\hline Transferring bed to chair & $\begin{array}{l}\text { Able to step or shuffle through standing to the chair. This involves } \\
\text { actively transferring weight from one leg to another to move to } \\
\text { the chair. If the patient has been stood with the assistance of a } \\
\text { medical device, they must step to the chair (not included if the } \\
\text { patient is wheeled in a standing lifter device) }\end{array}$ & 5 \\
\hline Marching on spot (at bedside) & $\begin{array}{l}\text { Able to walk on the spot by lifting alternate feet (must be able } \\
\text { to step at least four times, twice on each foot), with or without } \\
\text { assistance }\end{array}$ & 6 \\
\hline $\begin{array}{l}\text { Walking with assistance of two or } \\
\text { more people }\end{array}$ & $\begin{array}{l}\text { Walking away from the bed/chair by at least } 5 \text { meters ( } 5 \text { yards) } \\
\text { assisted by two or more people }\end{array}$ & 7 \\
\hline $\begin{array}{l}\text { Walking with assistance of one } \\
\text { person }\end{array}$ & $\begin{array}{l}\text { Walking away from the bed/chair by at least } 5 \text { meters ( } 5 \text { yards) } \\
\text { assisted by one person }\end{array}$ & 8 \\
\hline $\begin{array}{l}\text { Walking independently with } \\
\text { a gait aid }\end{array}$ & $\begin{array}{l}\text { Walking away from the bed/chair by at least } 5 \text { meters ( } 5 \text { yards) } \\
\text { with a gait aid, but no assistance from another person. In a } \\
\text { wheelchair-bound person, this activity level includes wheeling the } \\
\text { chair independently } 5 \text { meters ( } 5 \text { yards) away from the bed/chair }\end{array}$ & 9 \\
\hline $\begin{array}{l}\text { Walking independently without a } \\
\text { gait aid }\end{array}$ & $\begin{array}{l}\text { Walking away from the bed/chair by at least } 5 \text { meters ( } 5 \text { yards) } \\
\text { without a gait aid or assistance from another person }\end{array}$ & 10 \\
\hline
\end{tabular}

